\title{
ESTILOS DE COMUNICAÇÃO DE MARCAS GLOBAIS EM DIFERENTES CONTEXTOS CULTURAIS: UM ESTUDO SOBRE A MARCA MCDONALD'S
}

\section{COMMUNICATION STYLES OF GLOBAL BRANDS IN DIFFERENT CULTURAL CONTEXTS: A STUDY OF THE MCDONALD'S BRAND}

\author{
Edson Roberto Scharf \\ Doutor em Engenharia e Gestão do Conhecimento, \\ ênfase em Marketing pela Universidade Federal de \\ Santa Catarina; Docente e Pesquisador do Programa \\ de Pós-Graduação em Administração da \\ FURB - Universidade Regional de Blumenau \\ artigoes@gmail.com
}

Halissa Odebrecht da Silva Graduada em Comunicação Social pela FURB - Universidade Regional de Blumenau; Especialista em International Marketing (Halmstad University - Suécia) halissa@gmail.com.br

RESUMO

O objetivo do estudo é analisar os estilos de comunicação adotados pela marca McDonald's nos mercados norte-americano e brasileiro, com base nos conceitos de Mooij (1998). Com método de pesquisa qualitativo, a amostra é de escolha intencional, com o conjunto social composto por quatro comerciais (dois brasileiros e dois norte-americanos) para determinados produto McDonald's, totalizando doze filmes publicitários. Por meio da técnica de análise do conteúdo, os achados mostraram que as adaptações da comunicação são semelhantes nos dois países. Especificamente se obteve: a) quatro comerciais brasileiros foram classificados como de modo direto (voltados ao indivíduo) e apenas dois norte-americanos se enquadraram nesta modalidade, contrariando a definição usual sobre os brasileiros; b) a maior parte dos comerciais do Brasil tem sua comunicação verbal no tipo afetivo (orientada ao receptor da mensagem), enquanto nos comerciais norte-americanos a maior parte é instrumental (mensagem persuasiva de venda); c) as relações possíveis de similitudes ou diferenças em função do poder de compra não revelaram distanciamentos profundos. Palavras-chave: Estilos de comunicação publicitária. Branding. Adaptação de campanhas publicitárias. Estratégias de marketing global. Marcas globais. 


\section{INTRODUÇÃO}

Marcas são especialmente importantes em segmentos de alta competitividade, pois facilitam a decisão de compra do consumidor e minimizam o erro na escolha (DOUGLAS e CRAIG, 2003; AAKER, 2007; SIKKEL, 2013). A essência da marca, no entendimento de diversos autores (FARQUHAR, 1989; AAKER, 2007; KELLER e HALKIER, 2014), é de ser uma associação dos elementos da identidade da organização. Marca é um conceito tangível ou intangível que identifica unicamente uma oferta por meio de uma comunicação simbólica de funcionalidade e diferenciação, trazendo as influências de sustentabilidade que influenciam o valor oferecido, segundo o entendimento de Jevons (apud TYNAN et al., 2010). Basicamente, ela transporta os valores da organização para a mente do consumidor (KELLER e HALKIER, 2014).

Quando o envolvimento mercadológico se dá além das fronteiras da sede da empresa, com atuação em outros países do globo, a marca assume uma condição ainda mais relevante na manutenção dos aspectos que se identificam com a organização (STERN 2006; PAYNE et al., 2009). O esforço dos anunciantes é ampliado a fim de manter a mesma linha de raciocínio no planejamento e na criação da comunicação da marca devido às condições diferentes nos mercados ao redor do mundo.

Nesse contexto, a questão de pesquisa busca saber se determinada empresa global adota estilos de comunicação diferentes conforme o contexto cultural do país em que atua.

O objetivo do trabalho foi analisar os estilos de comunicação adotados pela marca McDonald's nos mercados norteamericano e brasileiro, com base nos conceitos de Mooij (1998). Os objetivos específicos foram: a) analisar os comerciais de produtos McDonald's veiculados nos Estados Unidos da América e no Brasil; b) identificar as alterações ocorridas na comunicação desses produtos nos dois países para o mesmo produto; e c) analisar as motivações das adaptações ocorridas na comunicação desses produtos de um país para o outro.

O estudo é relevante na medida em que procura analisar os estilos de comunicação de uma mesma marca, em países diferentes, ampliando o entendimento e a discussão da importância de adotar ou não estratégias de comunicação para a marca de forma personalizada para públicos distintos. 
2 CAMPANHAS GLOBAIS DE COMUNICAÇÃO: ENTENDIMENTOS INICIAIS

O desenvolvimento de atividades capazes de promover produtos, de comunicar valores e de destacar benefícios, fortalece as marcas e o relacionamento entre a organização e os clientes no longo prazo (AAKER, 2007; KELLER e HALKIER, 2014). Para Clark et al. (2009), a comunicação está definida como um investimento dinâmico na lembrança da marca e na qualidade percebida. A propaganda, por envolver emoção, une o consumidor à marca de maneira sólida (EISEND, 2013).

Para Etzel et al. (2001), quatro fatores interferem na determinação das estratégias de comunicação: mercado-alvo, recursos financeiros disponíveis para a promoção, natureza e estágio no ciclo de vida do produto. Especificamente quanto ao mercado-alvo, devem ser observados os estágios pelos quais o consumidor passa até realizar a decisão de compra: percepção (saber da existência de determinada marca); conhecimento (saber as características de um produto); apreciação (maneira como o mercado se sente diante do produto); preferência (distinguir da concorrência e preferir a marca); convicção (aumentar a necessidade pelo produto); e compra.

Uma posição mais dirigida à discussão da globalização da comunicação é defendida por Moraes (2003), para quem a concentração multinacionalizada dirige a cadeia produtiva da atividade publicitária. Para o autor, este processo decorre de fatores tais como a integração de mercados pelos avanços tecnológicos; a globalização das marcas; a concorrência entre os grupos de comunicação e a centralização das decisões estratégicas nas holdings; e o alinhamento das contas multinacionais. É bastante comum a cooperação entre as unidades filiais dos negócios internacionais sobre a comunicação criada, visando alinhamento global e diminuição de custos (BUCKLEY e CASSON, 2011).

$$
\text { Para Blackwell et al. (2005), }
$$
empresas que se voltam para a propaganda a fim de se comunicar com novos consumidores do mundo inteiro, globalizando seus negócios, têm que decidir entre realizar campanhas globais ou localizadas. Há características de produtos e mensagens que tendem a ter maior aceitação com a adoção de uma abordagem globalizada, quando: a base da mensagem possa ser definida com estilos de vida similares; a propaganda apelar para as necessidades e as emoções humanas 
básicas; o produto satisfazer aos desejos universais. Segundo os autores, campanhas globais, apesar da imagem unificada, usam linguagem ou estereótipos para manter o poder de diferenciação dos sentimentos associados com o produto. Para Eisend (2013) e Kavaratzis e Hatch (2013) as especificidades e características do local em que a comunicação é veiculada podem fazer parte da decisão de criação publicitária e seu resultado pode auxiliar na consecução dos objetivos emocionais, tais como reconhecimento da marca e construção da identidade (EISEND, 2013; KAVARATZIS e HATCH, 2013). Para Andrade (2005), há, ainda, a denominada abordagem 'glocal', neologismo resultante da união de 'global' com 'local', significando o meio termo entre essas duas abordagens.

Em recentes trabalhos, a propaganda cuja estratégia é adaptada tem se mostrado mais efetiva nos resultados obtidos (MOOIJ e HOFSTEDE, 2010; WONG e MERRILEES, 2007; OKAZAKI et al., 2006). Nesse sentido, Mooij e Hofstede compreendem que cada povo, representado pelo conjunto de valores de cada um dos indivíduos, pode representar diferentes formatos de comunicação pelas empresas que os desenvolvem. Os conceitos que a pessoa tem de si mesma, sobre sua identidade e personalidade, fazem com que os esforços de branding e de comunicação sejam explanados de forma variada conforme a cultura de determinado povo (MOOIJ e HOFSTEDE, 2010).

Anunciantes internacionais se deparam com diversas barreiras quando comunicam seus produtos a consumidores estrangeiros. Entre as principais dificuldades estão a língua, as restrições culturais, as atitudes locais em relação à propaganda, a estrutura deficiente de mídia e as regulamentações de propaganda (KOTABE e HELSEN, 2000). Os aspectos econômicos e os de controle de elaboração da mensagem pesam a favor de uma abordagem global (JUNG, 2003). Argumentos como peças produzidas e distribuídas ao mesmo tempo (gerando economia); consistência e homogeneização da mensagem (um único padrão criativo); e rapidez na entrega das peças são defendidos para o uso da comunicação global (CAILLAT e MUELLER, 1996). A rapidez com que as comunicações podem ser alteradas, adaptadas e aperfeiçoadas, faz com que uma abordagem global seja rapidamente compreendida por pessoas com hábitos muito diferentes entre si em função dos países culturalmente diferentes (HUGHES, 2013). O autor defende, ainda, 
que os consumidores da atualidade buscam produtos interessantes no mundo inteiro e, com isso, o conteúdo da comunicação se torna global.

No entanto, cada cultura pode ter concepções diferentes sobre a propaganda. Enquanto no Egito as pessoas dizem que ela não melhora em nada o produto, na China as pessoas decidem a marca que irão comprar baseadas na propaganda. Sobre a infraestrutura de mídia, são grandes as dificuldades na escolha das mídias corretas. Nos Estados Unidos e no Japão, a quantidade de mídia disponível é extensa, enquanto na China é difícil encontrar mídia que tenha dados confiáveis quanto à sua situação no mercado (KOTABE e HELSEN, 2000). Como o mundo tem se tornado "menor", devido basicamente à internet, os mercados têm se adequado para ofertar mais espaços midiáticos, o que também faz com que haja uma padronização das possibilidades de veiculação (KAVARATZIS e HATCH, 2013).

A primeira campanha global do McDonald's, "Amo muito tudo isso", iniciou em setembro de 2003 e teve os primeiros comerciais veiculados na televisão em maio de 2004, quando oito filmes publicitários foram ao ar em diferentes países. A mensagem 'I'm lovin' $i t$ " em sua trilha sonora tinha adaptações baseadas nos públicos locais. "Nós sabemos que para alcançar o sucesso, esta ideia de marca global teria que ser flexível o suficiente para ser totalmente aceita e compreendida pelos nossos funcionários e clientes. Com certeza a campanha 'I'm lovin' it' adequa-se a isto", disse Larry Lights, vice-presidente executivo de Marketing Global do McDonald's (apud HOWARD, 2004).

\section{DO CONCEITO DE MARCA ÀS MARCAS GLOBAIS}

Uma marca busca facilitar a troca entre o consumidor e o produtor. Como ativo fundamental da corporação, é tratada como uma estratégia de longo prazo (KUMAR et al., 2013), principalmente porque muitas organizações já iniciam as suas atividades de convencimento e valorização da marca se comunicando com pessoas cada vez mais jovens (TOOMEY e FRANCIS, 2013). Marcas são relevantes tanto para as organizações quanto para os consumidores (CHERNATONY, 2001; AAKER, 2007) e criam valor para o consumidor através da sua essência: ser um símbolo reconhecido e facilitar a escolha, reduzindo o risco percebido pelo consumidor (KAPFERER, 2004). 
Ao alcançar a internacionalização, deve ser verificada a relação dos valores nacionais que a marca segue e adaptar estes aos valores dos países receptores (TAVARES, 2008). Segundo Holden (2006), ao lançar uma marca global é necessário perceber se ela atende às necessidades dos consumidores globais, saber quais seriam as adaptações aos diferentes comportamentos, rendas e culturas, e mensurar se a oportunidade da globalização compensa os esforços tomados.

Para que o branding global seja implantado devem ser observados variados fatores, segundo Holden (2006): a padronização global deve complementar a customização local (a primeira fornecendo consistência e a segunda permitindo a flexibilidade necessária em relação ao preço, à distribuição e ao marketing integrado); as qualidades da marca (a superioridade do produto e seu posicionamento único são estabelecidos em nível global, e devem ser informados à equipe local); as estratégias de preço (são melhores quando feitas localmente); e o marketing integrado (oportunidades de conquistar consumidores em novos mercados, por meio das experiências com a marca). Para Douglas e Craig (2003), também os parceiros estratégicos são fundamentais. Por exemplo, quando a agência de comunicação responsável pela propaganda é global, permite o controle centralizado do esforço publicitário do anunciante, tendo facilitadas a manutenção dos clientes e a expansão global. Além disto, processos de branding adequadamente gerenciados permitem se chegar ao brand equity planejado pela organização, para que a marca seja valorizada além das fronteiras do país de origem (KUMAR et al., 2013).

É de se observar que a marca McDonald's, anteriormente constituída a partir de padrões e regras duramente estabelecidas, segundo Fontenelle (2007), na atualidade passa a determinar a estratégia da organização.

\section{OS ESTILOS DE COMUNICAÇÃO NA ATIVIDADE DE PROPAGANDA}

Os estilos de comunicação para as atividades globais de marketing são estudados por diversos autores. Entre eles, Sklair (1991) e Golding e Harris (1996) tratam de movimentos globais e práticas corporativas transnacionais, não evidenciando a comunicação, embora seja citada; Real (1998) trata da cultura global, ampliando essa dimensão para além do objetivo definido; Harvey et al. (2001) e 
Maguire et al. (2002) discutem basicamente a mídia e o esporte em conjunto, o que inviabiliza suas pesquisas para este estudo. Nesse sentido, Mooij (1998) contribui mais adequadamente aos fins do trabalho ao trazer à luz os esforços de propaganda e a identidade de marca. Pesquisadores que também trabalham nessa linha de estudo são Cho (1999) e Holden (2002) que versam sobre a globalização da propaganda. No Brasil, Vilches (1997) e Andrade (2005) têm dado relevância ao tema. A escolha por Mooij (1998) se deu pela afinidade entre os estilos de comunicação propostos e o tema deste estudo, tendo havido entendimento de que as contribuições desse autor são pontuais para os resultados desejados neste trabalho. Convém ressaltar, dessa forma, que para melhor compreensão dos diferentes estilos de comunicação é necessário entender distintos tipos de propaganda. Com base em Mooij (1998) seguem os estilos de comunicação utilizados em comerciais publicitários:

a) Contexto: ocorre em duas dimensões. A denominação de contexto implícito ocorre quando a maior parte das informações está ínsita na propaganda. Normalmente, em culturas em que as pessoas trocam muitas informações com os familiares, os amigos e os clientes, os relacionamentos tendem a ser mais próximos. A denominação de contexto explícito ocorre quando a maior parte da mensagem tem forma verbalizada ou escrita. Em culturas em que as pessoas não trocam muitas informações entre si, com relacionamentos mais frios, a comunicação tende a ter pouco contexto. Países como Itália, Portugal e Espanha preferem propagandas com muito contexto; já países como Estados Unidos, Alemanha e Inglaterra preferem as propagandas com pouco contexto. Maingueneau $(2004,1998)$ apresenta os índices de contextualização, ou seja, signos que permitem a identificação, determinando o que é falado e em que gênero. Alguns índices possuem presença em massa: local, sexo, idade, gestos, vestimenta, sinais de pertinência (aliança, medalhas e outros). A contextualização pode também tratar de traços verbais, indicando uma região de origem, um grupo social ou uma profissão (MAINGUENEAU, 2004).

b) Modo: a autora entende que o modo de comunicação é direto quando enfatiza a orientação de valores individuais, a lógica linear e as interações verbais diretas. O estilo individualista de comunicação verbal e não verbal sugere que intenções e 
significados estejam explícitos na mensagem. O modo de comunicação é indireto quando enfatizada a orientação para os valores de grupos, a lógica circular e a orientação verbal indireta. Culturas individualistas (anglo-saxônica e do norte europeu) preferem o modo direto, enquanto culturas coletivas (da maior parte da Ásia, do mundo Árabe e da América Latina) optam pelo modo de comunicação indireto.

c) Comunicação verbal: estilo dividido em comunicação direta/indireta; elaborada/sucinta; pessoal/contextual; e instrumental/afetiva. $\mathrm{Na}$ comunicação direta, as vontades, os desejos e as necessidades são explícitos e na indireta, as mensagens verbais ocultam a real intenção do narrador (termos como 'com certeza' e 'definitivamente' para intenções de compra são exemplos de comunicação direta; na indireta usam-se palavras como 'provavelmente' e 'talvez'). $\mathrm{Na}$ comunicação elaborada, há o uso de linguagem rica e expressiva enquanto na sucinta se usam palavras menos expressivas, pausas e silêncios. Pode ocorrer um terceiro tipo denominado de comunicação exata, que ocorre quando são fornecidas informações estritamente necessárias para a situação proposta
(Mooij, 1998). O estilo de comunicação pessoal é feito pela linguagem centrada no individualismo, enquanto o estilo da linguagem tipo contextual é centrada na situação. O primeiro estilo é orientado à pessoa, reforçando o 'eu' (Inglaterra), enquanto o segundo enfatiza o sentido de um contexto relacionado com o papel de identidade (Japão e China). O estilo de comunicação instrumental orienta a linguagem ao remetente, com o tipo afetivo orientado ao receptor da mensagem. O orador que usa o estilo instrumental conscientemente constrói a mensagem com a finalidade de persuadir e produzir uma mudança de atitude. O estilo afetivo é baseado no pressuposto de que os seres humanos irão adaptar-se ao seu ambiente ao invés de explorá-lo. Esse estilo é direcionado à cultura coletivista e de contexto implícito.

d) Comunicação não verbal: a preferência por esse estilo está ligada à cultura de inserção e é de contexto implícito ou explícito, envolvendo metáforas visuais, testemunho, dramatização entre outras linguagens. Esse estilo de comunicação também é definido por culturas voltadas ao indivíduo ou ao coletivo. A Figura 1 especifica os países mais adaptados com cada estilo de comunicação. 
Figura 1 - Estilos de comunicação e propaganda não verbal

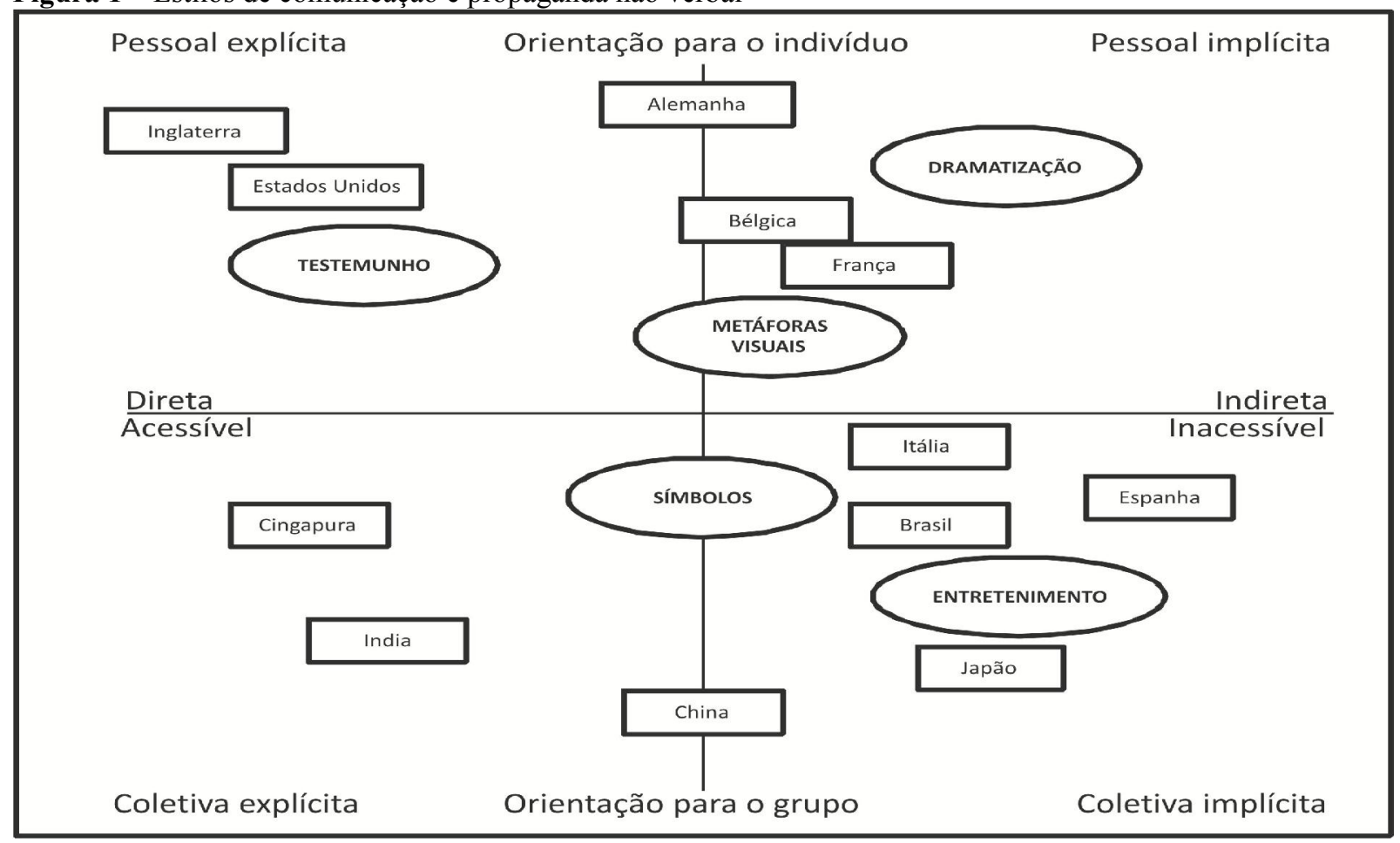

Fonte: Mooij (1998, p. 163)

A comparação entre os estilos de comunicação de brasileiros e norteamericanos é apresentada no Quadro 1. As questões econômicas se sobressaem, mas também devem ser considerados, entre outros aspectos, a colonização dos países, a língua, a gestão do conhecimento, a separação entre as classes sociais e a capacidade de consumo dos povos.

Quadro 1 - Estilos de comunicação no Brasil e nos Estados Unidos da América

\begin{tabular}{|c|c|c|c|}
\hline \multicolumn{2}{|c|}{ ESTILO } & BRASIL & ESTADOS UNIDOS \\
\hline \multicolumn{2}{|c|}{ Contexto } & Implícita & Explícita \\
\hline \multicolumn{2}{|c|}{ Modo } & Indireta & Direta \\
\hline \multirow{4}{*}{$\begin{array}{c}\text { Comunicação } \\
\text { verbal }\end{array}$} & Direta/indireta & Indireta & Direta \\
\hline & Elaborada/sucinta & Elaborada & Exata \\
\hline & Pessoal/contextual & Contextual & Pessoal \\
\hline & Instrumental/afetiva & Afetiva & Instrumental \\
\hline \multicolumn{2}{|c|}{ Comunicação não verbal } & $\begin{array}{l}\text { Entretenimento/ } \\
\text { Metáforas visuais }\end{array}$ & Testemunho \\
\hline
\end{tabular}

Fonte: adaptado de Mooij (1998, p. 296) 
Uma decisão a ser tomada quando há o desenvolvimento de uma campanha global é sobre a sua padronização ou a sua adaptação nos variados mercados. A padronização significa que um ou mais elementos da campanha de comunicação são mantidos. Para Cho et al. (1999) a mensagem é referente às ideias que estão sendo comunicadas e a execução é a forma como o conteúdo é expresso, com seus elementos característicos (de estilo, visual e sonoro). As principais vantagens de uma padronização global são as economias de escala; a imagem consistente; a interfertilização (estímulo às filiais para adotarem propagandas bem-sucedidas em outros mercados); e os segmentos similares de consumidores globais (KOTABE e HELSEN, 2000).

Uma campanha é considerada padronizada quando o próprio produto é a mensagem, basicamente sem sons ou narrativas. Pode servir como uma campanha do tipo 'guarda-chuva', complementando propagandas locais, ou em propagandas institucionais. A campanha não pode diferenciar o produto por valores específicos, para não ocasionar problemas culturais (MOOIJ, 1998). Uma campanha é considerada semipadronizada quando as imagens se constituem na parte central da propaganda. Às vezes, a narração da língua original (inglês) é usada e, em outras, é feita uma sobreposição, dublando a narrativa. Esse tipo pode atravessar fronteiras apenas com uma dublagem.

$\mathrm{Na}$ estratégia adaptada, são usados vários elementos de execução que podem ser modificados dependendo do lugar onde serão inseridos. A combinação de apelos pode não ser tão efetiva com as adaptações quanto a sua forma original, pois aspectos culturais específicos podem ficar comprometidos (MOOIJ, 1998). Essa campanha é chamada de 'glocal', desenvolvida a partir da formulação de estratégias e elementos discursivos globais, conjuntamente com recomendações de acordo com o país onde a campanha será veiculada (ANDRADE, 2005).

A estratégia de multiexecução ocorre quando a empresa anuncia produtos similares, porém com nomes diferentes para cada cultura, incidindo em formas básicas e consistentes de anunciar, como testemunho, comparações, ou adaptando pessoas, língua e cultura. A estratégia de plataforma única combina elementos comuns nas propagandas, como o nome da marca e a embalagem, a música, os símbolos, e utiliza diferentes execuções baseadas nas culturas onde será inserida. A vantagem desta estratégia é a combinação 
de valores locais e uma ideia central reconhecível entre as propagandas. A última estratégia é a multilocal. Essa é a estratégia das companhias que entendem que irão apenas lucrar ao explorar os valores da cultura local. Este tipo de propaganda constrói relacionamentos com os consumidores e objetivam a confiança deles com a comunicação (MOOIJ, 1998).

$\mathrm{O}$ quadro 2 é a adaptação de Andrade (2005) para as definições dos tipos de abordagem publicitária, descritas originalmente por Mooij (1998).

Quadro 2 - Tipos de abordagem utilizados pela propaganda

\begin{tabular}{|c|c|c|}
\hline TIPO & DEFINIÇÃo & CARACTERÍSTICAS \\
\hline 1 & Totalmente padronizada & Predominância de imagens. Não baseada em valores. \\
\hline 2 & Semipadronizada & $\begin{array}{c}\text { Mesmo formato, execução padrão, geralmente com adaptações do } \\
\text { tipo "voz off" e/ou dublagens. }\end{array}$ \\
\hline 3 & Adaptada & Mesmo formato, variando elementos de execução. \\
\hline 4 & Multiexecução & Tema padronizado, execuções locais adaptadas à cultura. \\
\hline 5 & Plataforma única & Conceito padronizado, com execuções locais. \\
\hline 6 & Multilocal & Recursos globais para abordagem local. \\
\hline
\end{tabular}

Fonte: Andrade (2005, p. 9)

\section{MÉTODO E TÉCNICAS DE PESQUISA}

O estudo analisou os estilos de comunicação dos produtos McDonald's nos mercados brasileiro e norte-americano, sendo o conjunto social composto pelos comerciais dos produtos McLanche Feliz, Big Mac e McMenu. A investigação adotou o método qualitativo, em pesquisa com delineamento exploratório, com análise documental dos roteiros dos filmes, e de análise do conteúdo como técnica de interpretação de unidades de significados. Foram analisados doze comerciais, sendo quatro de cada produto escolhido conforme critérios anteriormente definidos, dois de cada país: Brasil e Estados Unidos da América. Seguem as especificidades do delineamento metodológico adotado.

$\mathrm{O}$ método utilizado foi $\mathrm{o}$ de pesquisa qualitativa, sendo indicada, segundo Vieira e Tibola (2005) para desvendar aspectos subjetivos do pensamento humano e suas relações com o cotidiano. Também Malhotra (2001) suporta essa escolha ao defender que o método qualitativo facilita a compreensão do contexto do problema. A adoção do 
método condicionou o delineamento exploratório da pesquisa, uma vez que pesquisas desse tipo proporcionam familiaridade com o problema, para melhor explicitação ou construção de hipóteses. O uso da pesquisa exploratória, segundo Barros e Lehfeld (1986), significa utilizar métodos muito amplos e versáteis.

A amostra foi definida de maneira intencional, não probabilística, em função dos objetivos da pesquisa. Dessa maneira, os comerciais que comunicam os atributos de venda ou institucionais dos produtos McLanche Feliz, Big Mac e McMenu, todos da empresa McDonald's, se constituíram no foco de interesse, dentre todos os demais produtos da empresa. Essa escolha foi proveniente da análise realizada em um conjunto encontrado na busca de 68 peças publicitárias, selecionadas antecipadamente. A análise se constituiu da visualização dos filmes no depositário denominado Youtube (YOUTUBE 2009a; 2009b; 2009c; 2009d; 2008a; 2008b; 2008c; 2007a; 2007b; 2007c; 2006) e nos sítios da própria empresa pesquisada (McDONALD'S, 2009; 2009b; 2009c; 2008; McDONALD'S UK, 2009).

Para manutenção da coerência, a escolha obedeceu aos seguintes critérios, em ordem de importância: filmes desenvolvidos para um único produto, diferentes nos dois países e os mais recentes. Foram escolhidos e posteriormente analisados doze comerciais, sendo quatro de cada produto, dois de cada nacionalidade: brasileira e norteamericana. O quadro 3 mostra a seleção da amostra de pesquisa.

Especificamente em relação aos filmes publicitários, foram feitos os downloads e transcritos os roteiros, com a observação da entonação das falas dos personagens, a participação de cada elemento em cena e o conjunto estético da peça, com o fito de minimizar desvios de análise e acrescentar elementos intangíveis ao tema. 
Quadro 3 - Comerciais publicitários do McDonald's no Brasil e nos Estados Unidos da América

\begin{tabular}{|c|c|c|c|}
\hline PRODUTO & PAÍS & TÍTULO & ANO \\
\hline $\begin{array}{c}\text { McLanche } \\
\text { Feliz1 }\end{array}$ & Brasil & Personagens Hanna Barbera & 2008 \\
\hline $\begin{array}{c}\text { McLanche } \\
\text { Feliz2 }\end{array}$ & Brasil & Hello Kitty & 2007 \\
\hline $\begin{array}{c}\text { McLanche } \\
\text { Feliz1 }\end{array}$ & Estados Unidos & Speed Racer & 2008 \\
\hline $\begin{array}{c}\text { McLanche } \\
\text { Feliz2 }\end{array}$ & Estados Unidos & Cha Cha Slide & 2007 \\
\hline Big Mac1 & Brasil & Óbvio & 2007 \\
\hline Big Mac2 & Brasil & Parônimos & 2006 \\
\hline Big Mac1 & Estados Unidos & Big Mac Chant & 2008 \\
\hline Big Mac2 & Estados Unidos & Bigger Than The Big Mac & 2007 \\
\hline McMenu1 & Brasil & McMenu & 2009 \\
\hline McMenu2 & Brasil & McCalabresa & 2006 \\
\hline McMenu1 & Estados Unidos & Money’s Worth & \\
\hline McMenu2 & Estados Unidos & Better Than 1 Dollar Lasik & \\
\hline
\end{tabular}

Fonte: Coletado pelos autores (2011)

A técnica utilizada para a análise dos dados foi a denominada de análise de conteúdo (SCHRADER, 1974; FONSECA Jr., 2005; BARDIN, 2010). A análise do material coletado seguiu os passos recomendados por Bardin (2010), ocorrendo na pré-análise a organização do material e a escolha dos documentos a serem analisados. Como o presente estudo é de caráter exploratório e não se estabeleceu hipótese para o problema, os procedimentos de análise se basearam no uso de um padrão descritivo.

$\mathrm{Na}$ organização, a leitura sistemática do material coletado possibilitou a identificação e a classificação das unidades de significados, surgindo proposições norteadoras, em função de teorias conhecidas. Assim, com a exploração do material, a análise dos temas gerados previamente pelo referencial teórico foi revelada para os dados 
coletados. O texto de análise foi formado pelo conjunto de roteiros dos comerciais e dividido por unidades de registro (VERGARA, 2006; BARDIN, 2010).

Foram escolhidas as frases ou palavras com base nas questões e categorias consideradas relevantes segundo o que estabeleceu Mooij (1998) quanto aos estilos de comunicação e, secundariamente, de acordo com Andrade (2005) quanto aos tipos de abordagem da propaganda. Para tanto, se buscou fragmentar a mensagem em partes para identificar padrões de similaridades e diferenças (LEISS; KLINE; JHALLY, 1997). Em cada roteiro foram definidas unidades de significados e, em seguida, se iniciou o mapeamento dos dados, tomando por base os aspectos fundamentados teoricamente.

Após essa definição, foram identificadas as principais relações existentes entre os temas propostos para cada um dos produtos e países, emergindo os resultados. Os temas foram definidos conforme duas condições: a homogeneidade e a pertinência. Segundo Vergara (2006) o critério de homogeneidade afirma que um único princípio de classificação deve reger a organização dos temas. A pertinência se refere à adaptação aos conteúdos e ao objetivo da pesquisa. Nessa fase, foram construídos quadros para uma melhor visualização do encontrado, divididos em categorias, sendo observadas a frequência e a relevância de elementos encontrados em cada comercial, bem como a presença ou a ausência de tais elementos.

\section{RESULTADOS DE PESQUISA}

Para este estudo foi realizada a análise dos comerciais do McDonald's, sendo quatro do McLanche Feliz (dois brasileiros e dois norte-americanos); quatro do Big Mac (dois brasileiros e dois norteamericanos); e quatro do McMenu (dois brasileiros e dois norte-americanos), totalizando doze filmes publicitários.

Os estilos de comunicação, segundo Mooij (1998), são os de contexto, modo, comunicação verbal e comunicação não verbal. O Quadro 4 detalha o estilo de comunicação mais utilizado em cada comercial analisado. 
Quadro 4 - Estilos de comunicação

\begin{tabular}{|c|c|c|c|c|c|c|c|}
\hline \multirow[t]{2}{*}{ Comerciais } & \multirow{2}{*}{$\begin{array}{l}\text { Contexto } \\
\text { (explícito / } \\
\text { implícito) }\end{array}$} & \multirow{2}{*}{$\begin{array}{c}\text { Modo } \\
\text { (direto / } \\
\text { indireto) }\end{array}$} & \multicolumn{4}{|c|}{ Comunicação verbal } & \multirow{2}{*}{$\begin{array}{c}\text { Comunicação } \\
\text { não verbal }\end{array}$} \\
\hline & & & $\begin{array}{l}\text { direta / } \\
\text { indireta }\end{array}$ & $\begin{array}{c}\text { elaborada / } \\
\text { sucinta }\end{array}$ & $\begin{array}{l}\text { pessoal / } \\
\text { contextual }\end{array}$ & $\begin{array}{c}\text { instrumental } \\
\text { / afetiva }\end{array}$ & \\
\hline $\begin{array}{c}\text { McLanche } \\
\text { Feliz Brasil } \\
1\end{array}$ & Implícito & Direto & Direta & Exata & Pessoal & Afetiva & $\begin{array}{c}\text { Metáforas } \\
\text { visuais }\end{array}$ \\
\hline $\begin{array}{c}\text { McLanche } \\
\text { Feliz Brasil } \\
2\end{array}$ & Explícito & Direto & Direta & Elaborada & Pessoal & Afetiva & Testemunho \\
\hline $\begin{array}{c}\text { McLanche } \\
\text { Feliz EUA } \\
\quad 1\end{array}$ & Implícito & Direto & Direta & Exata & Pessoal & Afetiva & Entretenimento \\
\hline $\begin{array}{l}\text { McLanche } \\
\text { Feliz EUA } \\
\quad 2\end{array}$ & Implícito & Indireto & Indireta & Sucinta & Contextual & Instrumental & Entretenimento \\
\hline $\begin{array}{l}\text { Big Mac } \\
\text { Brasil } 1\end{array}$ & Explícito & Direto & Direta & Elaborada & Pessoal & Afetiva & Dramatização \\
\hline $\begin{array}{l}\text { Big Mac } \\
\text { Brasil } 2\end{array}$ & Explícito & Indireto & Direta & Elaborada & Contextual & Instrumental & Dramatização \\
\hline $\begin{array}{c}\text { Big Mac } \\
\text { EUA } 1\end{array}$ & Implícito & Indireto & Direta & Exata & Contextual & Instrumental & Entretenimento \\
\hline $\begin{array}{l}\text { Big Mac } \\
\text { EUA } 2\end{array}$ & Implícito & Indireto & Direta & Elaborada & Contextual & Instrumental & Dramatização \\
\hline $\begin{array}{c}\text { McMenu } \\
\text { Brasil } 1\end{array}$ & Implícito & Indireto & Direta & Elaborada & Contextual & Afetiva & Dramatização \\
\hline $\begin{array}{c}\text { McMenu } \\
\text { Brasil } 2\end{array}$ & Explícito & Direto & Direta & Elaborada & Pessoal & Afetiva & Testemunho \\
\hline $\begin{array}{c}\text { McMenu } \\
\text { EUA } 1\end{array}$ & Implícito & Indireto & Direta & Exata & Contextual & Instrumental & Dramatização \\
\hline $\begin{array}{c}\text { McMenu } \\
\text { EUA } 2\end{array}$ & Explícito & Direto & Direta & Elaborada & Contextual & Afetiva & Dramatização \\
\hline
\end{tabular}

Fonte: Elaborado pelos autores (2011)

Pela análise realizada, os comerciais dos Estados Unidos da América têm no seu contexto a apresentação implícita, enquanto os brasileiros são notadamente explícitos. É de se dar relevo ao fato de que um único comercial norteamericano tenha sido classificado como explícito. Isolada, essa informação pode ser apenas demonstrativa. Entretanto, como se verá no decorrer dos resultados, ela se conecta com importância a variados aspectos do desenvolvimento de comerciais para marcas consolidadas.

Quanto ao modo da propaganda, 
enquanto quatro comerciais brasileiros foram classificados como diretos (voltados ao indivíduo), apenas dois americanos se enquadraram nessa especificação. A interação verbal direta é característica de culturas individualistas, conforme Mooij (1998), contrariando o modo comumente explicado para definir os brasileiros.

Quanto à comunicação verbal, dentre todos os comerciais, apenas um, norte-americano, foi classificado como indireto, já que é musical. No entanto, a letra do jingle desse comercial também poderia ser compreendida como de comunicação verbal direta. Não foi assim classificada porque tem uma configuração bastante diferente da linguagem dos demais comerciais. Em referência à comunicação verbal elaborada, sucinta ou exata, os resultados se apresentaram em quantidades muito distintas, com sete escolhas e a maioria nos comerciais brasileiros. O uso da linguagem rica e com expressão, se utilizando de provérbios, metáforas e expressões 'floreadas' (MOOIJ, 1998), é própria da propaganda brasileira, conforme diversos autores (TAVARES, 2008; SCHARF，2006). A comunicação exata obteve quatro classificações, entre as doze possíveis, três delas em comerciais dos Estados Unidos, uma cultura reconhecidamente mais individualista e centrada em comunicação de menor ênfase no conjunto e maior destaque a uma proposta única de valor. Corroborando essa posição, a única seleção feita para a comunicação denominada sucinta também é de um comercial norteamericano. No entendimento de Mooij (1998, p. 161), “[...] o silêncio entre as palavras é repleto de significados [...]”, característica de quem usa a comunicação verbal de forma menos extrovertida.

Quatro comerciais brasileiros são pessoais (centrado no individualismo) e cinco peças norte-americanas são contextuais (centradas na situação). A linguagem pessoal reforça o "eu", dando um sentido de personalização enquanto a linguagem contextual está relacionada com a identidade, reforçando a ideia de situação vigente, o status quo (Mooij, 1998). Os comerciais produzidos nos Estados Unidos trazem implícito o sentimento que a população tem em relação a si mesma, demonstrada pela força e pelo orgulho que os move diante dos desafios. As pessoas têm mais liberdade de autoexpressão, o que é feito através do seu padrão de valores (MOOIJ, 2000), e a comunicação destes mesmos consumidores é muito dependente dos seus valores culturais (MOOIJ, 2004).

A maior parte dos comerciais do Brasil tem sua comunicação verbal no tipo 
afetivo (orientada ao receptor da mensagem). Nos comerciais norteamericanos, a maior parte é instrumental (orientada ao remetente). $\mathrm{O}$ tipo de comunicação afetiva tem o dobro da participação no Brasil em comparação aos Estados Unidos que, de acordo com Mooij (1998), é aquela baseada no pressuposto de que as pessoas irão se adaptar ao seu ambiente, ao invés de iniciar a exploração. O tipo instrumental se caracteriza por construir a mensagem com a finalidade de persuadir e produzir uma mudança de atitude. Nos anuários de propaganda, é visível a quantidade de anúncios e comerciais norte-americanos com essa abordagem, de geração de efeitos possivelmente imediatos de venda no segmento de atuação. Esforços de propaganda são desenvolvidos para, também, influenciar fortemente as pessoas a consumir determinados produtos (EISEND, 2013). No entanto, o autor defende que a propaganda, notadamente em organizações globais e de marcas fortes, é veiculada buscando obter o reconhecimento da marca. Considerando que parte do esforço publicitário da empresa pesquisada se dirige às crianças, se infere que a propaganda realmente alcance seu intento, apesar das forças contrárias. Por exemplo, as agências governamentais e os grupos de proteção ao indivíduo têm realizado grandes esforços no sentido de minimizar o impacto da propaganda no comportamento dos adolescentes e limitar a sua influência junto a esses grupos (KINARD e WEBSTER, 2010).

As relações de semelhanças ou diferenças entre brasileiros e norteamericanos do ponto de vista do poder de compra não revelam distanciamentos profundos. Apesar da conhecida diferença em prol do poder de compra americano, os comerciais mais voltados ao preço não são os brasileiros. Essa faceta é identificável quando $o$ ator principal do filme publicitário se transforma no estereótipo do "pão-duro", aquele que por centavos faz loucuras. Um dos filmes mostra um pai de família quebrando toda a calçada com uma britadeira. Ao chegar em casa com uma bolsa do McDonald's, a esposa pergunta se a ferramenta não era apenas para furar um degrau da escada que apresentava problemas. O marido responde que pagou o aluguel por meio dia, então precisava fazer valer o dinheiro gasto. A mulher termina oferecendo um lanche a um preço realmente convidativo (mesmo para o seu marido). É uma demonstração da faceta relativa ao hábito de consumo, levando em consideração as questões financeiras. 
Propagandas norte-americanas, na comunicação não verbal, apresentam apenas os estilos de dramatização e entretenimento (três vezes cada estilo), enquanto nos comerciais brasileiros a dramatização é a que aparece com maior frequência (três vezes), seguida do testemunho (duas vezes). O formato de testemunhal, principalmente quando feito com celebridades, é um modo eficaz de se promover determinado produto e obter resultados rápidos (CORRÊA, 2006;
SCHARF, 2006; APEJOYE, 2013), pois no Brasil as pessoas associam rapidamente pessoas famosas às coisas boas da vida, inclusive produtos com qualidade.

O Quadro 5 apresenta a abordagem global utilizada ao se comparar os comerciais brasileiros com seus correspondentes norte-americanos. Ele aponta aspectos importantes de avaliação para entender a ocorrência de similitudes na atuação mercadológica adotada pelos países estudados.

Quadro 5 - Estratégia global de comunicação

\begin{tabular}{|c|c|}
\hline $\begin{array}{c}\text { BRASIL/ESTADOS UNIDOS } \\
\text { DA AMÉRICA }\end{array}$ & ABORDAGEM UTILIZADA PELA PROPAGANDA GLOBAL \\
\hline McLanche Feliz 1 & Multiexecução \\
\hline McLanche Feliz 2 & Multilocal \\
\hline Big Mac 1 & Multilocal \\
\hline Big Mac 2 & Multilocal \\
\hline McMenu 1 & Multiexecução \\
\hline McMenu 2 & Multilocal \\
\hline
\end{tabular}

Fonte: Elaborado pelos autores (2011), baseado em Andrade (2005) e Mooij (1998)

Nas estratégias e no raciocínio criativo da campanha global "Amo muito tudo isso" (I'm lovin' it, no original em inglês), o McDonald's priorizou os esforços denominados de multilocal, utilizando recursos de uma empresa global e adotando uma abordagem regional nas peças publicitárias, o que não foi evidenciado no Brasil. Neste caso, há a conexão dos benefícios da globalização na distribuição, no marketing e na escala de produção, aceitando que processos mentais não podem ser padronizados (MOOIJ, 1998). Os processos mentais se referem ao fato de como as pessoas pensam, aprendem, percebem, categorizam e processam as informações recebidas (MOOIJ e HOFSTEDE, 2010). 
Das seis comparações, quatro delas foram classificadas nessa abordagem. O zelo na construção da identidade de marca, considerando os aspectos culturais e econômicos diferentes para distintas regiões, preconiza que organizações globais se preocupem com questões locais, como se fossem organismos locais. É a oportunidade, na visão de Hooley et al. (2005), de as empresas escolherem os mercados em que atuarão para concentrar seus esforços na construção de relacionamentos no longo prazo. Para a construção da identidade de marca e posterior posicionamento sólido, é necessária uma proposta de valor que consiga dialogar com culturas diversas se utilizando da mesma mensagem ou fazendo pequenas adaptações (KUMAR et al., 2013; KELLER e HALKIER, 2014). "Um dos segredos das marcas sólidas é a manutenção da coerência ao longo do tempo" (AAKER, 2007, p. 332). Duas são classificadas no estilo multiexecução, no qual produtos similares, com nomes de marcas diferentes, são divulgados em comerciais que incidem em uma forma de anunciar similar.

O Quadro 6 traça um comparativo dos quatro estilos de comunicação identificados por Mooij (1998), para os dois países participantes da pesquisa.

Quadro 6 - Comparativo dos estilos de comunicação: Brasil e Estados Unidos da América

\begin{tabular}{|c|c|c|c|}
\hline \multicolumn{2}{|l|}{ ESTILO } & BRASIL & ESTADOS UNIDOS \\
\hline \multicolumn{2}{|l|}{ Contexto } & explícito -4 & implícito - 5 \\
\hline \multicolumn{2}{|l|}{ Modo } & direto -4 & indireto - 4 \\
\hline \multirow[t]{4}{*}{ Comunicação verbal } & direta/indireta & direta -6 & direta -5 \\
\hline & elaborada/sucinta & elaborada - 5 & exata -3 \\
\hline & pessoal/contextual & pessoal - 4 & contextual -5 \\
\hline & instrumental/afetiva & afetiva -5 & instrumental -4 \\
\hline \multicolumn{2}{|c|}{ Comunicação não verbal } & dramatização - 3 & $\begin{array}{c}\text { dramatização - } 3 \\
\text { entretenimento - } 3\end{array}$ \\
\hline
\end{tabular}

Fonte: Dados da pesquisa (2011) 


\section{CONCLUSÃO}

O objetivo deste trabalho foi identificar os estilos de comunicação adotados pela marca McDonald's no Brasil e nos Estados Unidos. A base conceitual a respeito dos paradoxos culturais nos mercados globais manifestados na propaganda é a de Mooij (1998) e os tipos de abordagem, adotados complementarmente, foram os delineados por Andrade (2005).

Os resultados da pesquisa indicam que embora a identidade de marca tenha sido mantida, ocorrem determinadas adaptações locais, considerando as características da população e da linguagem utilizada. $\mathrm{O}$ aspecto mais relevante aponta para modificações necessárias na comunicação da marca devido ao maior uso do construto 'preço' pelo mercado norteamericano. As relações possíveis de similitudes ou diferenças em função do poder de compra não revelam distanciamentos profundos. Apesar da conhecida diferença em prol do poder de compra americano, os comerciais mais voltados ao preço não são os brasileiros. $\mathrm{O}$ brasileiro adota, costumeiramente, duas iniciativas em relação aos negócios de fastfood sofisticados, como é entendido o McDonald's no Brasil: primeiro, assume pagar caro pelo lanche, herança da colonização norte-americana nos empreendimentos que contêm marca global; segundo, considera como condição social niveladora de compra, que o diferencia de quem não pode comprar, visto que o lanche da marca é considerado caro para os padrões brasileiros.

Quanto aos estilos de comunicação, os resultados que obtiveram concordância se relacionam aos fatores da comunicação não verbal, com o uso da dramatização, que é um dos principais elementos constitutivos do raciocínio criativo na propaganda, juntamente com o humor.

Quanto à comunicação verbal, no Brasil ela é direta (explícita), elaborada (com linguagem rica), pessoal (centrada no individualismo) e afetiva (orientada ao receptor da mensagem). Nos Estados Unidos, a comunicação verbal é direta (explícita), exata (é fornecida apenas a informação essencial), contextual (centrada na situação) e instrumental (orientada ao remetente). A propaganda apresenta estilos diferentes: enquanto no Brasil, o contexto do estilo de comunicação é explícito, com a maior parte da mensagem na forma verbalizada, nos Estados Unidos, é implícito, com a mensagem ínsita.

O modo no Brasil é direto e nos Estados Unidos é indireto. Possivelmente, 
esta é uma das limitações do trabalho, pois é sabido que o povo americano é mais introvertido e reservado do que o brasileiro, geralmente mais expansivo e alegre na comunicação. A análise do tipo elaborada/sucinta na comunicação verbal confirma essa tese. Caso o estudo abrangesse quantidade maior de produtos ou se estendesse a um conjunto de marcas, mesmo nos dois países, os resultados poderiam ser diferentes.

Como estratégia global adotada, o estilo multilocal foi classificado com maior frequência. Neste sentido, a individualidade e o poder de compra dos consumidores foram preservados segundo a cultura desses clientes, mantendo, porém, determinadas características essenciais da marca. Nos Estados Unidos, com um povo mais individualista nas relações pessoais, os comerciais publicitários com heróis de histórias em quadrinhos ou de filmes famosos são constantes, como mote principal da peça. No Brasil, as situações em que a família é participante do almoço, com o pai ou a mãe, ou ambos, em momentos de descontração com os filhos no ambiente do McDonald's são comuns, pois parcela importante do conceito da empresa no país é de relação (pais-filhosinteração). Em ambos os comerciais, o benefício funcional (sabor e rapidez) e o benefício emocional (felicidade, prazer e gratificação) estão presentes, compondo a parcela de benefícios globais da marca.

A avaliação das informações coletadas, da análise do conteúdo e dos resultados obtidos permite compreender que a marca global McDonald's tem campanhas distintas para os seus produtos, sem perder a proposta única de raciocínio para cada um deles. Variam os estilos de comunicação, dada a diversidade da economia e da cultura, mas marcas sólidas podem ser edificadas com a criação das campanhas publicitárias com base em aspectos de conceituação muito próximos. Especificamente quanto ao individualismo manifestado pelo povo norte-americano, as campanhas demonstraram que há uma preferência por comerciais que mostram com exatidão os benefícios funcionais ou emocionais, sem necessidade de um contexto. O Brasil, por ter um povo ligado aos aspectos de conjunto, demonstra ser mais suscetível a compreender e apreciar comerciais em que o cenário faça parte da mensagem e em que haja interação entre pessoas, geralmente com a acentuação de uma ideia maior ao invés da valorização de um único indivíduo ou benefício. 


\subsection{Implicações acadêmicas}

As principais implicações teóricas podem ser observadas se ampliada a discussão sobre os estilos de comunicação global. Estudado por autores diversos (ver SKLAIR, 1991; GOLDING e HARRIS, 1996; REAL, 1998; CHO, 1999; HARVEY et al., 2001; HOLDEN, 2002; MAGUIRE et al., 2002, e, no Brasil, ver ANDRADE, 2005; e VILCHES, 1997) o tema relacionado aos estilos de comunicação adotados pelas marcas globais nos diferentes países em que atuam, carece de aprofundamento nas pesquisas de marketing, principalmente no estabelecimento dos elementos e das dimensões que compõem essas marcas (HOLDEN, 2002; CHO, 1999). Além disso, o artigo colabora com a discussão acerca da análise das adaptações realizadas nos comerciais publicitários em razão da cultura de povos diferentes, com investigação do impacto desses comerciais no contexto das atividades mercadológicas atuais, mais especificamente na comunicação publicitária para marcas globais.

\subsection{Implicações gerenciais}

As implicações gerenciais deste trabalho se referem principalmente ao processo de branding para marcas globais.
Os aspectos apresentados relativos aos comerciais e produtos estudados foram discutidos sucedendo ao esforço publicitário, ou seja, as dimensões avaliadas que constroem o valor de uma marca se baseiam nos estilos de comunicação adotados pela marca global. Estudos dessa natureza podem servir de base para as decisões de investimentos na área de marketing e, sobretudo, de auxílio nas decisões a respeito do direcionamento, da conceituação e do desenvolvimento da propaganda para a marca global, além de discussão sobre as principais diretrizes a serem tomadas quanto à propaganda para diferentes grupos culturais.

\section{PUBLICAÇÃO}

Trabalho originalmente apresentado no SEMEAD/USP 2010.

\section{REFERÊNCIAS}

\section{AAKER, D. A. Construindo marcas}

fortes. Rio de Janeiro: Bookman, 2007.

ANDRADE, J. Motivos para uso de campanhas globais: diferenças entre percepções de profissionais de agências de propaganda e de anunciantes. In: XXIX Encontro da Anpad, Anais..., Rio de Janeiro, 2005.

APEJOYE, A. Influence of Celebrity Endorsement of Advertisement on Students' Purchase Intention. Mass

Communication and Journalism, v.3, n.3, 
p. 150-168, 2013.

BARDIN, L. Análise de conteúdo. 4. ed. Lisboa: Edições 70, 2010.

BARROS, A. J. P. e LEHFELD, N. A. S. Fundamentos de metodologia: um guia para a iniciação científica. São Paulo: McGraw-Hill, 1986.

BLACKWELL, R. D.; MINIARD, P. W.; ENGEL, J. F. Comportamento do consumidor. São Paulo: Pioneira Thomson Learning, 2005.

BUCKLEY, P. J.; CASSON, M. Marketing and the multinational: extending internalisation theory. Journal of the Academy Marketing Science, v. 39, n. 4, p. 492-508, 2011.

CAILLAT, Z.; MUELLER, B. Observations: the influence of culture on American and British Advertising. Journal of

Advertising Research, v. 36, n. 3, p. 7988, May/June 1996.

\section{CHERNATONY, L. From brand vision to} brand evaluation. Oxford: ButterworthHeinemann, 2001.

CHO, B. et al. Cultural values reflected in theme and execution: a comparative study of U.S. and Korean television commercials. Journal of Advertising, $\mathrm{v}$. 28, n. 4, p. 59-74, 1999.

CLARK, C. R.; DORASZELSKI, U.; DRAGANSKA, M. The effect of advertising on brand awareness and perceived quality: an empirical investigation using panel data. Quantitative Marketing and Economics, vol. 7, n. 2, p. 207-236, June 2009.

CORRÊA, R. Comunicação integrada de marketing: uma visão global. São Paulo: Saraiva, 2006.
DOUGLAS, S.; CRAIG, S. International Advertising, In: International

Encyclopedia of Social and Behavioral Sciences, Smelser, N. J. e Baltes, P. Editors in Chief, Media Studies and Commercial Applications, M. Schudson, 2. ed., Amsterdam: Pergamon, 2001.

EISEND, M. The moderating influence of involvement on two-sided advertising effects. Psychology and Marketing, v. 30, n. 7, p. 566-575, 2013.

ETZEL, M. J.; WALKER, B. J.;

STANTON, W. J. Marketing. São Paulo: Makron Books, 2001.

FARQUHAR, P. Managing brand equity. Marketing Research, v. 1, n. 3, p. 24-33, 1989.

FONTENELLE, I. A. Construção e desconstrução de fronteiras e identidades organizacionais: história e desafios do McDonald's. RAE- Revista de administração de empresas, v. 47, n. 1, p. $60-70,2007$.

GOLDING, P.; HARRIS, P. Beyond cultural imperialism: globalization, communication and the new international order. London: Sage, 1996.

HARVEY, J.; LAW, A.; CANTELON, M. North American Professional Sport Team Franchises, Ownership Patterns and Global Entertainment Conglomerates. Sociology of Sport Journal, v. 4, n. 2, p. 435-457, 2001.

HOLDEN, B. Construindo marcas globais. In: TYBOUT, A. M.; CALKINS, T. (org.). Branding. São Paulo: Atlas, p. 287-310, 2006.

HOLDEN, T. J. M. Color coding: globalization and the ad. International Scope Review, v. 4, n. 8, p. 1- 23, 2002. 
HOOLEY, G. J.; SAUNDERS, J. A.; PIERCY, N. F. Estratégia de marketing e posicionamento competitivo. 3 . ed. São Paulo: Pearson Prentice Hall, 2005.

HOWARD, L. McDonald's electronic press kit: McDonald's rolls out new "I'm Lovin' It" commercials as campaign connects with customers worldwide. 2004. Disponível em:

$<$ http://mcdepk.com/ilicreative/downloads/l ead_release.pdf $>$. Acesso em: 11 ago. 2011.

HUGHES, D. E. This ad's for you: The indirect effect of advertising perceptions on salesperson effort and performance. Journal of the Academy of Marketing Science, v. 41, n. 3, p. 1-18, 2013.

JUNG, J. Foreign direct investment by transnational advertising agencies: analysis of merger \& acquisition and joint venture activities, 2003. Disponível em: <http://www.tukkk.fi/mediagroup/5VV MEC\%20PAPERS/Jung.pdf>. Acesso em: 27 out. 2011.

KAPFERER, J-N. As marcas, capital da empresa: criar e desenvolver marcas fortes. 3. ed. Porto Alegre: Bookman, 2004.

KAVARATZIS, M.; HATCH, M. J. The dynamics of place brands: An identitybased approach to place branding theory. Marketing Theory, v. 13, n. 1, p. 69-86, 2013.

KELLER, M.; HALKIER, B. Positioning consumption: A practice theoretical approach to contested consumption and media discourse. Marketing Theory, v. 14, n.1, p. 35-51, 2014.

KOTABE, M.; HELSEN, K. Administração de marketing global. São Paulo: Atlas, 2000.
KUMAR, R. S.; DASH, S; PURWAR, P. $\mathrm{C}$. The nature and antecedents of brand equity and its dimensions. Marketing Intelligence \& Planning, v. 31, n. 2, p. 141-159, 2013.

LEISS, W.; KLINE, S.; JHALLY, S. Social communication in Advertising: persons, products and images of well-being. Londres: Routledge (1997).

MAGUIRE, J.; POULTON, E.; POSSAMAI, C. The War of the words? Identity politics in anglo-german press coverage of EURO 96. European Journal of Communication, v.14, n.1, p. 61-90, 2002.

MAINGUENEAU, D. Análise de textos de comunicação. São Paulo: Cortez, 2004.

MAINGUENEAU, D. Termos-chave da análise do discurso. Belo Horizonte: UFMG, 1998.

MALHOTRA, N. K. Pesquisa de marketing: uma orientação aplicada. 3. ed. Porto Alegre: Bookman, 2001.

MORAES, D. O capital da mídia na lógica da globalização. In: MORAES, Dênis (org.). Por uma outra comunicação: mídia, mundialização cultural e poder. Rio de Janeiro: Record, 2003, p. 187-216.

MOOIJ, M. Translating advertising: painting the tip of an iceberg. The Translator, v. 10, n. 2, p. 179-198, 2004.

MOOIJ, M. The future is predictable for international marketers: converging incomes lead to diverging consumer behavior. International Marketing Review, v. 17, n. 2, p. 103-113, 2000.

MOOIJ, M. Global market and advertising: understanding cultural paradoxes. Thousand Oaks: Sage, 1998. 
MOOIJ, M.; HOFSTEDE, G. The Hofstede model: applications to global branding and advertising strategy and research.

International Journal of Advertising. v. 29, n. 1, p. 85-110, 2010.

OKAZAKI, S.; TAYLOR, C. R.; ZOU, S. Advertising standardization's positive impact on the bottom line. Journal of Advertising. v. 35, n. 3, p. 17-33, 2006.

PAYNE, A., STORBACKA, K., FROW, P.; KNOX S. Co-creating brands:

diagnosing and designing the relationship experience. Journal of Business Research, v. 62 , n. 3, p. 379-389, mar 2009.

REAL, M. R. MediaSport: Technology and the Commodification of Post-modern Sport in Wenner. New York: Routledge, 1998.

SCHARF, E. R. Administração na propaganda. Rio de Janeiro: Qualitymark, 2006.

SCHRADER, A. Introdução à Pesquisa Social Empírica. Porto Alegre: Globo, 1974.

SIKKEL, D. Brand relations and life course: Why old consumers love their brands. Journal of Marketing Analytics, v. 1, n. 2, p, 71-80, 2013.

SKLAIR, L. Sociology of the Global System. London: Harvester, 1991.

STERN, B. B. What does brand mean? Historical-analysis method construct definition. Journal of the Academy of Marketing Science, v. 43, n. 2, p. 216-223, 2006.

TAVARES, M. C. Gestão de marcas: construindo marcas de valor. São Paulo: Harbra, 2008.
TOOMEY, D. A; FRANCIS, A. L. Branded product placement and pre-teenaged consumers: influence on brand preference and choice. Young Consumers, v. 14, n. 2, p. 180-192, 2013.

TYNAN, C.; McKECHNIE, S.; CHHUON, C. Co-creating value for luxury brands.

Journal of Business Research, v. 63, n.11, p. 1156-1163, 2010.

VERGARA, S. C. Métodos de pesquisa em administração. São Paulo: Atlas, 2006.

VIEIRA, V. A.; TIBOLA, F. Pesquisa qualitativa em marketing e suas variações: trilhas para as pesquisas futuras. Revista de Administração Contemporânea, v. 9, n. 2, p. 9-34, 2005.

VILCHES, L. Globalização comunicativa e efeitos culturais. In: MORAES, D. (org.)

Globalização, mídia e cultura contemporânea. Campo Grande: Letra Livre, 1997. p. 77-113.

WONG, H.Y.; MERRILEES, B. Multiple roles for branding in international marketing. International Marketing Review, v. 24, n. 4, p. 384-408, 2007.

\section{PESQUISA E REFERÊNCIAS DE COMERCIAIS}

MCDONALD'S. Institucional: quem somos. (2009). Disponível em: $<$ http://www.mcdonalds.com.br/instituciona 1/mcdonalds_brasil_quemsomos.asp $>$. Acesso em: $\overline{1} 3$ set. $\overline{2} 011$. International franchising information. Oak Brook, (2009b). Disponível em: $<$ http://www.aboutmcdonalds.com/mcd/fra nchising.html >. Acesso em: 12 set. 2011. 
Disponível em:

McDonald's history. (2009c).

$<$ http://www.aboutmcdonalds.com/mcd/our company/mcd_history.html $>$. Acesso em:

12 out. 2011.

Disponível em:

$<$ http://www.mcdonalds.co.uk/static/pdf/ab outus/education/mcd_marketing.pdf $>$.

Acesso em: 15 set. 2011.

WIKIPEDIA, the free

encyclopedia. [S. 1.]: Wikimedia

Foundation, 2009d. Disponível em:

$<$ http://en.wikipedia.org/wiki/McDonald\%2

$7 \mathrm{~s}>$. Acesso em: 15 out. 2011.

.WIKIPEDIA, a enciclopédia livre.

[S. 1.]: Wikimedia Foundation, 2009e.

Disponível em:

$<$ http://pt.wikipedia.org/wiki/McDonald\%2

7s>. Acesso em: 15 set. 2011.

MCDONALD'S UK. Make up your own

mind: questions answered. 2009.

Disponível em:

$<$ http://www.makeupyourownmind.co.uk/q uestion-

search?key $=$ how + many + restaurants + each + country\#question5>. Acesso em: 5 out.

2011.

YOUTUBE. McLanche Feliz Hanna

Barbera. Usuário: CanalTaterka. 2008a.

Disponível em:

$<$ http://www.youtube.com/view_play_list?p

$=0 \mathrm{D} 13989482 \mathrm{C} 33631>$. Acesso em: 12 out. 2011.

YOUTUBE. McLanche Feliz Hello Kitty. Usuário: catarinamagna. 2007a. Disponível em:

$<$ http://www.youtube.com/watch? $\mathrm{v}=\mathrm{zP}-$ txZTvFYc>. Acesso em: 20 set. 2011.
YOUTUBE. McDonald's Speed Racer

Happy Meal commercial. Usuário:

HornsbyAndJohnson. 2008b. Disponível em:

$<$ http://www.youtube.com/watch? $\mathrm{v}=$ cCecto

7gDos>. Acesso em: 15 set. 2011.

YOUTUBE. McDonald's Happy Meal ad

Cha Cha Slide commercial. Usuário:

1ttsrh. 2007b. Disponível em:

$<$ http://www.youtube.com/watch?v=0eN9K

P61OZs>. Acesso em: 20 set. 2011.

YOUTUBE. Óbvio. Usuário:

gabrielluciana. 2008c. Disponível em:

$<$ http://www.youtube.com/watch? $=$ CU_M

JZaX7IQ>. Acesso em: 18 out. 2011.

YOUTUBE. Parônimos - McDonald's 2.

Usuário: celoffc. 2006. Disponível em:

$<$ http://www.youtube.com/watch? v=kAyks

1eGhlM>. Acesso em: 18 out. 2011.

YOUTUBE. McDonald's Big Mac.

Usuário: McDonaldsUS. 2009a. Disponível em:

$<\mathrm{http}$ ://www.youtube.com/watch? $\mathrm{v}=\mathrm{zCn} 0$ sr2Xrw>. Acesso em: 20 set. 2011.

YOUTUBE. Bigger than the Big Mac. Usuário: megadeadlyz. 2007c. Disponível em:

$<$ http://www.youtube.com/watch? $\mathrm{v}=\mathrm{ni} 47 \mathrm{Nz}$ Rs2WI>. Acesso em: 17 set. 2011.

YOUTUBE. McMenu 2009. Usuário:

CanalTaterka. 2009b. Disponível em:

$<$ http://www.youtube.com/watch?v=3J20uI yx4DQ>. Acesso em: 14 set. 2011.

YOUTUBE. McDonald's “Money's Worth" Dollar Menu. Usuário:

DDBChicago. 2009c. Disponível em:

$<\mathrm{http}$ ://www.youtube.com/watch? $\mathrm{v}=\mathrm{ZmSN}$ _iRLFyg >. Acesso em: 18 out. 2011. 
YOUTUBE. McDonald's commercial better than 1 dollar lasik. Usuário: 1923814. 2009d. Disponível em:

$<\mathrm{http}: / /$ www.youtube.com/watch?v=APfAn j-F1tA>. Acesso em: 18 out. 2011.

ZAMBONE, N. Sabor com legenda. Portal da propaganda, 2006. Disponível em:

$<$ http://www.portaldapropaganda.com/vitri ne/tvporta1/2006/03/0007?data $=2006 / 03>$.

Acesso em Acesso em: 16 set. 2011. 